\title{
Differentiation Between Tendinous, Myotendinous and Myofascial Injuries by L-BIA in Professional Football Players
}

\author{
Lexa Nescolarde ${ }^{*}$, Joaquim Terricabras ${ }^{2,3}$, Sandra Mechó ${ }^{2,4}$, Gil Rodas ${ }^{2}$ and \\ Javier Yanguas ${ }^{2 *}$
}

${ }^{1}$ Department of Electronic Engineering, Universitat Politècnica de Catalunya, Barcelona, Spain, ${ }^{2}$ Medical Department, Futbol Club Barcelona, FIFA Medical Center of Excelence, Barcelona, Spain, ${ }^{3}$ Department of Surgery, Faculty of Medicine,

Universitat Autònoma de Barcelona, Barcelona, Spain, ${ }^{4}$ Department of Radiology, SCIAS-Hospital de Barcelona, Barcelona, Spain

OPEN ACCESS

Edited by:

Emiliano Cè,

University of Milan, Italy

Reviewed by:

Stefano Longo,

University of Milan, Italy

Rod Whiteley,

Aspetar Hospital, Qatar

*Correspondence:

Lexa Nescolarde

lexa.nescolarde@upc.edu

Javier Yanguas

xavier.yanguas@fcbarcelona.cat

Specialty section:

This article was submitted to

Exercise Physiology,

a section of the journal

Frontiers in Physiology

Received: 18 June 2020

Accepted: 14 August 2020

Published: 04 September 2020

Citation:

Nescolarde L, Terricabras J, Mechó S, Rodas $G$ and Yanguas J

(2020) Differentiation Between

Tendinous, Myotendinous and Myofascial Injuries by L-BIA in Professional Football Players.

Front. Physiol. 11:574124. doi: 10.3389/fphys.2020.574124
Purpose: To differentiate by localized bioimpedance (L-BIA) measurements $24 \mathrm{~h}$ after injury, between tendinous, myotendinous junction (MTJ), and myofascial junction (MFJ) injuries, previously diagnosed by MRI exam. To evaluate by L-BIA, the severity of MTJ injuries graded from 1 to 3 , and to determine the relationship between days to return to play (RTP) and L-BIA measurements.

Methods: 3T MRI and tetra polar L-BIA was used to analyzed 37 muscle injuries $24 \mathrm{~h}$ after injury in 32 male professional football players, $\left(23.5 \pm 1.5 \mathrm{~kg} \mathrm{~m}^{-2} ; 1.8 \pm 0.1 \mathrm{~m}\right.$; 20-30 year.) between the 2016-2017 and 2017-2018 seasons. Muscle injuries were classified by The British Athletics Muscle Injury Classification (BAMIC). Percentage difference of L-BIA parameters [resistance $(R)$, reactance $\left(X_{C}\right)$, and phase angle $(P A)$ ] of the injured side were calculated considering contralateral non-injured side as the reference value.

Results: According to BAMIC classification and by MRI exam, we found tendinous $(n=4)$, MTJ $(n=26)$, and MFJ $(n=7)$ muscle injuries. In addition, MTJ injuries were grouped according to the severity of injury in grade $1(n=11)$, grade $2(n=8)$, and grade $3(n=7)$. Significant decrease $(P<0.01)$ was found in the L-BIA parameters $R$, $X_{\mathrm{C}}$, and PA, in both MTJ and MFJ as well as in the different grades of MTJ injuries. In particular, in $\mathrm{XC}_{\mathrm{C}}(P<0.001)$, which is related to muscle cell disruption. Regarding days to RTP, there was statistical significance among the three different grades of MTJ injuries $(P<0.001)$, especially when grade 1 was compared to grade 3 and grade 2 compared to 3.

Conclusion: L-BIA is a complementary method to imaging diagnostic techniques, such as MRI and US, to quantify MTJ and MFJ injuries. In addition, the increase in the severity of the MTJ injury resulted in higher changes of the Xc parameter and longer time to RTP.

Keywords: localized bioimpedance, MRI, myotendinous junction, grade of muscle injury, professional football players 


\section{INTRODUCTION}

Muscle injures of lower limbs are the most common injury types in athletes (Junge et al., 2009; Engebretsen et al., 2013), accounting for more than $30 \%$ of injuries in professional football players (Ekstrand et al., 2011; Elliott et al., 2011). This trend seems to keep growing in professional male football players in Europe (Ekstrand et al., 2016).

An optimal diagnosis of muscle injury determines the severity of the injury, time to return to play (RTP) and risk of reinjury. However, determining the optimal RTP in professional football players is difficult due to the variability and complexity of the process. The decision of whether an athlete can safely RTP remains challenging (Askling et al., 2010) with $\sim 60 \%$ of reinjuries few weeks after RTP (Brooks et al., 2006; Heiderscheit et al., 2010). Imaging, either through magnetic resonance imaging (MRI) and/or ultrasound imaging (US) is key to assess muscle injuries and prognosis. However, it is still debated whether MRI report is a good predictor for time to RTP (Reurink et al., 2014). This is probably due to the lack of consensus in the diagnosis and classification of muscle injuries.

In the last 8 years, there have been proposed multiple different systems of muscle injury classifications based on clinical examination and radiological findings, especially through MRI (Mueller-Wohlfahrt et al., 2013; Pollock et al., 2014; Valle et al., 2017). The British Classification of Muscle Injuries of Athletics, BAMIC (Pollock et al., 2014), based on MRI findings, is one of the most internationally used and classifies muscle injuries according to anatomical location: myofascial, muscletendon junction, and intratendinous; as well as according to the severity of the injury, grading from 0 to 4 . Moreover, the BAMIC specifies that each hamstring muscle injury localization has different RTP. The criteria is based on the tissue type involved and the extent of the injury, being the intratendinous injury the one with longer time to RTP and higher recurrence rate (Patel et al., 2015; Pollock et al., 2016; Wangensteen et al., 2017).

The classification proposed by Pollock et al. (2014) agree with the idea of a histoarchitectural approach to skeletal muscle injury from Balius et al. (2020) describing that when myoconnective junction is affected, the injury can be located either in a MTJ (the injury affects an aponeurosis or a tendinous expansion attached to muscle fibers) or in the myofascial junction (MFJ) (when the injury involves muscle fiber and their perimysium and/or epimysium). And when an injury in the myoconnective junction has a tendon gap (by MRI), the injury will have worst prognosis, require longer time to RTP and could present greater risk of re-injury compared to others injuries. However, a study of full-thickness intramuscular tendon damage, did not show re-injury after 12 months (Vermeulen et al., 2019). Regarding MTJ and MFJ injuries, it is not clear which one has better prognosis and, consequently, less time to RTP (Balius et al., 2020).

Mono-frequency non-invasive electrical bioimpedance is associated with the injection of low-intensity sinusoidal current at $50 \mathrm{kHz}$ into a biological conductor resulting in measuring values of resistance (R), associated with the hydration state of soft tissue, and reactance (Xc) associated with the integrity of soft tissue structures (Lukaski, 1996; Lukaski and Piccoli, 2012, Lukaski, 2013). The current is delayed by the current flowing through the cell membranes (capacitive element, C). The $X_{\mathrm{c}}=$ $\frac{1}{2 \pi f C}$ is an indirect measure of the amount of applied current that penetrates to the cell membranes (Lukaski et al., 2019). That is, bioimpedance is a complex number $Z=\mathrm{R}-\mathrm{jXc}$, whose module, $Z$ is obtained by $\sqrt{(R)^{2}+(X c)^{2}}$ and phase angle $(\mathrm{PA})$ is the $\tan ^{-1}\left(X c_{R}\right)$.

When bioimpedance measurements are taken on a specific human body area, they are known as localized bioimpedance measurements (L-BIA). One of the first clinical applications of non-invasive L-BIA at $50 \mathrm{kHz}$ is related to electrical impedance myography (EIM) in neuromuscular diseases demonstrated significantly reduced values of $\mathrm{R}, \mathrm{Xc}$, and PA due to muscle fiber atrophy, connective tissue accretion, fat infiltration, and edema (Rutkove et al., 2008; Rutkove, 2009). Lukaski and Moore (2012), using L-BIA with phasesensitive BIA analyzer at $50 \mathrm{kHz}$, identified in lower leg wounds, a moderate decrease in R, Xc, and PA acutely after removing damaged tissue from a wound. Notably, the decreased occurred during infection and R, Xc, and PA values were restored after healing. Therefore, L-BIA could provide a safe and effective method to detect changes at cellular level.

In professional football players (Nescolarde et al., 2013, 2015), L-BIA measurements using $50 \mathrm{kHz}$ phase-sensitive BIA analyzer, are in agreement with the severity of muscle injury, diagnosed by MRI $24 \mathrm{~h}$ after injury, according to muscle gap and independently to anatomical location. L-BIA measurements $24 \mathrm{~h}$ after injury showed a significant reduction of $\mathrm{R}, \mathrm{Xc}$ and PA directly related to the severity of muscle injuries, being more noticeable in $\mathrm{Xc}$ than in $\mathrm{R}$. Moreover, more severe injuries showed larger percentage difference in Xc (\% difference) (Nescolarde et al., 2013, 2015). Sometimes there is a great challenge for the sports physicians and radiologists to be able to confirm diagnosis and especially the prognosis. Accurately quantifying the severity of muscle injury could help to improve the diagnosis of muscle injury.

This work aims (1) to differentiate by L-BIA, according to anatomical location, between tendinous, MTJ and MFJ injuries, previously diagnosed by MRI exam $24 \mathrm{~h}$ after injury; (2) to determine the severity of MTJ injuries graded from 1 to 3 by L-BIA; and (3) to determine the relationship between days to return to play (RTP) and L-BIA measurements $24 \mathrm{~h}$ after injury with severity of the injury.

\section{MATERIALS AND METHODS}

\section{Participants}

Futbol Club Barcelona (FCB) Medical Department studied prospectively 37 muscle injuries of 32 male professional football players, $\left(23.5 \pm 1.5 \mathrm{~kg} \mathrm{~m}^{-2} ; 1.8 \pm 0.1 \mathrm{~m} ; 20-\right.$ 30 year.) between the 2016-2017 and 2017-2018 seasons to assess and compare L-BIA and MRI findings. This 
study only evaluates injuries of football players (both during matches and training sessions) that presented acute muscle injury, to whom the medical team prescribed an MRI in the first $24 \mathrm{~h}$ after the injury, and in those cases that L-BIA study was performed during the same period of time.

\section{Magnetic Resonance Imaging (MRI)}

Magnetic resonance imaging is not only the gold standard technique of choice in professional football for diagnosing muscle injuries that has proven to be an essential tool in the assessment of muscle injuries in elite athletes, but is also rapidly becoming the imaging technique of choice for the evaluation of the connective tissue injuries (Schneider-Kolsky et al., 2006; Ekstrand et al., 2012). This imaging technique allows specialists to define muscle injury with excellent resolution of the three axes, including oblique planes, and assessing deep muscles by identifying the injury site from the origin, proximal myotendinous junction, muscle belly, distal junction or insertion point (Ahmad et al., 2013).

\section{MRI Protocol}

Magnetic resonance imaging was performed on 3T Canon Vantage Titan (Canon Medical Systems, Japan) in FCB Medical Center by a specialist musculoskeletal radiologist (SM) to classify the muscle injury. The specific MRI paramentrs are a maximum gradient strength of $45,203 \mathrm{~T} / \mathrm{m} / \mathrm{s}$ Slew Rate, and 32 receiver channels. Axial, Sagittal and Coronal T2 Fat Sat, TR 5200, 5000, and $3700 \mathrm{~ms}$, TE 44-60 ms, Eco train 7.5, SL 2.5-3.5 mm, in-plane resolution 0.9-1.4 $\mathrm{mm} \times 0.88-$ $0.97 \mathrm{~mm}$, FOV $256 \times 256,192 \times 272,288 \times 320 \mathrm{~mm}$, and Axial and Coronal TSE T1, TR 900-980 ms, TE $11 \mathrm{~ms}$, Eco train 7.5, SL 2.5-3.5 mm, in-plane resolution 0.71$0.9 \mathrm{~mm} \times 0.71-0.9 \mathrm{~mm}$, FOV $352 \times 352,288 \times 320 \mathrm{~mm}$ was acquired. On T2 Fat Sat sequences, muscle injuries are detected by the presence of hyperintense fluid accumulation. It is recommended to perform fluid-sensitive sequences (T2weighted in our case) with intermediate echo time (TE) (e.g., less than $65 \mathrm{~ms}$ ) to obtain an adequate contrast and spatial resolution of connective tissues. With these sequences we are able to detect edematous changes around the myotendinous, myoaponeurotic, and myofascial junctions, identify small tears in the connective tissue, as well as to delineate intra- or inter-muscular fluid collections or hematomas. T1-weighted sequences are useful in the assessment of hematic collections, in the detection of fatty muscular infiltration, as well as in the detection of scar tissue in chronic injuries that could be detected as chemical shift artifacts in the T2weighted sequences.

\section{Muscle Injury Grouping Through MRI Exam 24 h After Injury}

After MRI exam, 37 muscle injuries were categorized according to The British Athletics Muscle Injury Classification (Pollock et al., 2014) and considering the histoarchitectural approach to skeletal muscle injury (Balius et al., 2020) taking to account:

1. Myoconnective junction affected

- Tendinosis injuries are tears that extend into the tendon.

- Myotendinous junction (MTJ) injuries are high signal change occurs within the muscle or more commonly located exactly at the MTJ.

- Myofascial junction (MFJ) injuries extend from the fascia and demonstrate high signal change on fat-suppressed/STIR sequences within the periphery of the muscle.

\section{Severity of the injury, graded from 1 to 4}

- Grade 1 injuries are small tears. High signal in MRI extends less than $10 \%$ of the cross-sectional area (CSA) of the muscle and over a limited area of less than $5 \mathrm{~cm}$.

- Grade 2 shows hyper signal in MRI measure between 10 and $50 \%$ of CSA or extends between 5 and $15 \mathrm{~cm}$ within the muscle with a fiber disruption (gap) less than $5 \mathrm{~cm}$.

- Grade 3 injuries show high signal change patterns greater than $50 \%$ of the CSA or greater than $15 \mathrm{~cm}$ in length.

- Grade 4, complete muscle or tendon tears are not included in this study.

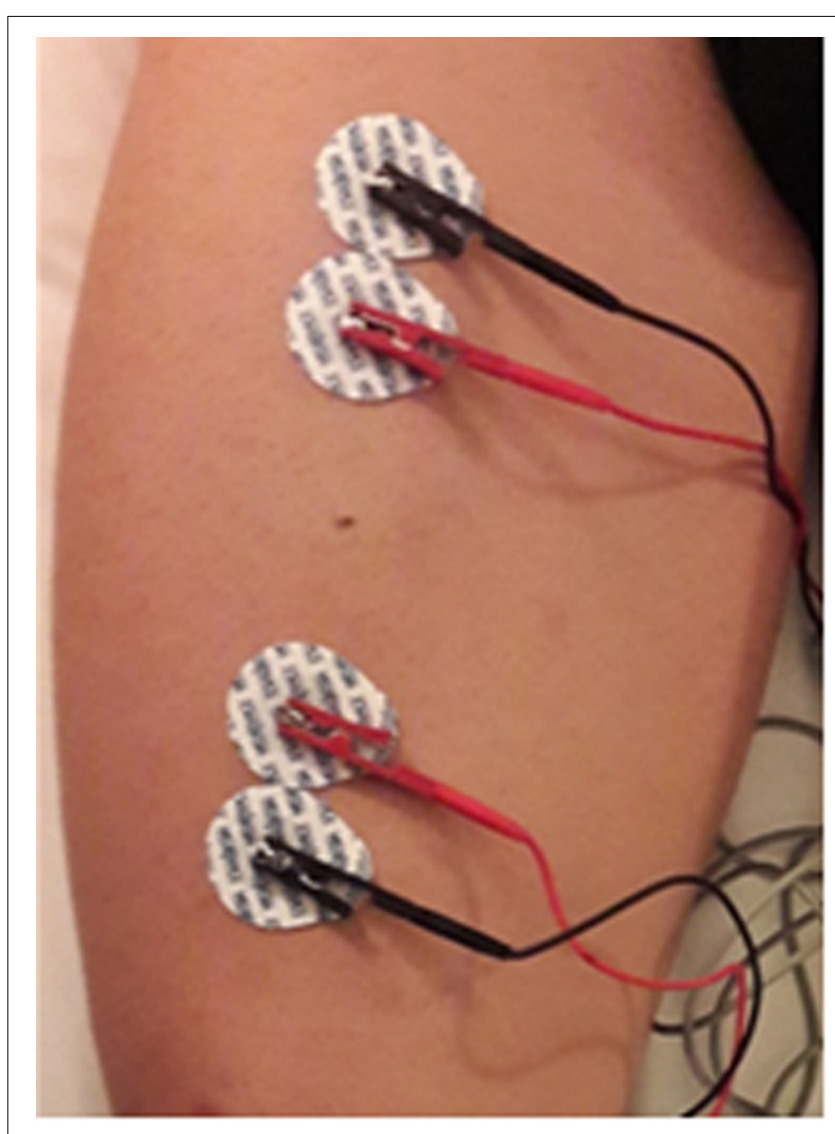

FIGURE 1 | Tetra-polar L-BIA electrode placement for intramuscular septum rectus femoris (MTJ). 

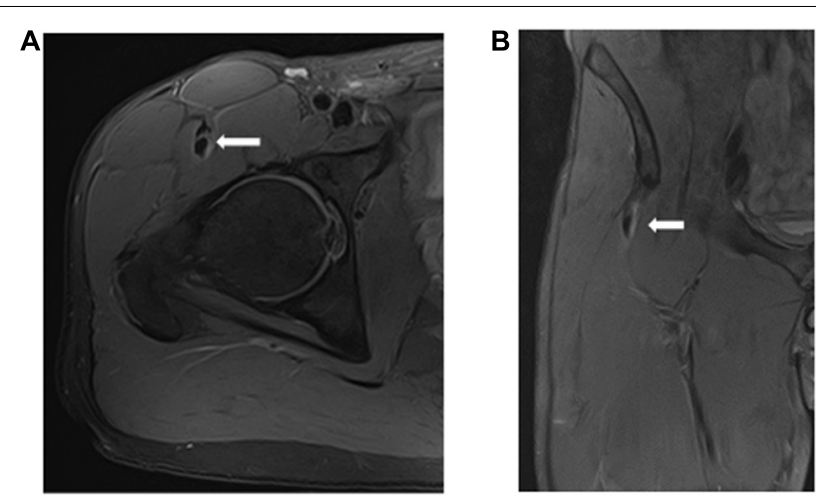

FIGURE 2 | Tendinous injury of the central tendon of rectus femoris (longitudinal tear of the central tendon with slight peritendinous edema) in axial (A) and coronal (B) T2 weighted fat-suppressed images.

\section{Localized Bioimpedance Measurements (L-BIA)}

Tetra polar L-BIA measurements, both in the injured side and the non-injured side, were performed $24 \mathrm{~h}$ after occurrence of the injury to quantify the percentage difference in $\mathrm{R}, \mathrm{Xc}$, and PA of injured side respect to the contralateral noninjured side. The impact of the severity of muscle injury was characterized by the percentage difference in L-BIA ( $\mathrm{R}, \mathrm{Xc}$, and PA). All injuries were diagnosed $24 \mathrm{~h}$ after injury by MRI exam. The variability of $\mathrm{R}$ and Xc (Nescolarde et al., 2015) between left and right non-injured muscle area were studied in 10 non-injured football players on three different days with an interval of 7-day between each measurement. The intraindividual differences in $1 / 3$ proximal quadriceps, $1 / 3$ medium quadriceps, $1 / 3$ proximal hamstrings and $1 / 3$ medium hamstrings ranged from -2.1 to $0.5 \Omega$ and the inter-individual differences were lower than $15 \%$ (2 SD).

The measurements were taken with a phase-sensitive impedance instrument BIA 101 Anniversary (Akern-Srl, Florence, Italy) that applied a constant sinusoidal alternating current of $245 \mu \mathrm{ARMS}$ at $50 \mathrm{kHz}$. The range of measure for resistance is $0-1500 \Omega$ and for reactance $0-500 \Omega$, with $2 \%$ maximum tolerance. Measurement errors determined with a parallel circuit of precision resistor and capacitor, were $<1 \Omega$ for $\mathrm{R}$ and $<2 \%$ for Xc.

The adhesive contact electrode $\mathrm{Ag} / \mathrm{AgCl}$ (COVIDIEN Ref. 31050522, COVIDIEN llc, Mansfield, IL, United States) with $\mathrm{R}$ and Xc intrinsic values of 10.89 and $0.30 \Omega$ respectively (Nescolarde et al., 2016), was chosen for L-BIA measurements. Similar to previous reports (Nescolarde et al., 2015, 2017) detector voltage electrodes (red) were placed $5 \mathrm{~cm}$ proximally and $5 \mathrm{~cm}$ distally, respectively, from the center of the injury located by US Aplio i800 (Canon Medical Systems, Japan). Two current injecting electrodes (black) were placed close to the detector voltage electrodes (Figure 1). Because of the proximity of the current-introducing and voltage-detecting electrodes, the inter-tester reproducibility (Nescolarde et al., 2013) of the R and Xc measurements

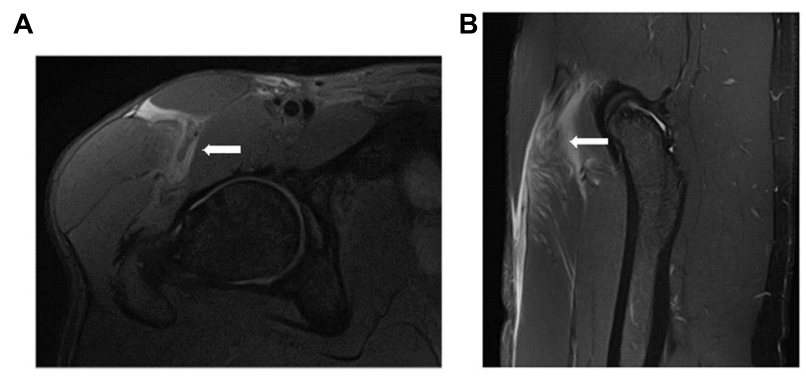

FIGURE 3 | Proximal MTJ injury of rectus femoris [connective tissue tear (arrow), and muscle fibers damaged with loss of pennation angle] in axial (A) and sagittal (B) T2 weighted fat suppressed images.

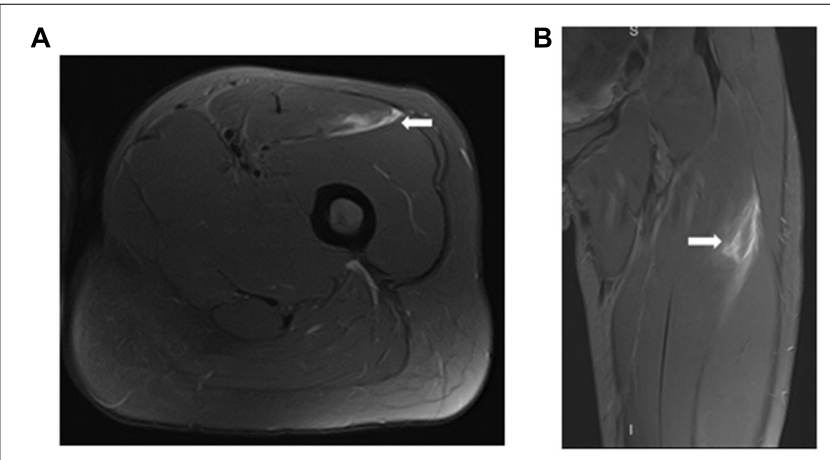

FIGURE 4 | Distal MFJ injury of rectus femoris (arrow) in axial (A) and coronal (B) T2 weighted fat-suppressed image.

was evaluated by 5 examiners. The range of variability was negligible, $1 \Omega$ for $\mathrm{R}$ and $0.45 \Omega$ for Xc. The mean $\pm \mathrm{SD}$ value of $\mathrm{R}$ and $\mathrm{Xc}$ were $39.6 \pm 0.6$ and $14.2 \pm 0.5 \Omega$ respectively, with coefficients of variation of $1.4 \%$ for $R$ and $3.2 \%$ for Xc.

In injuries located near the bone detector, voltage electrodes were placed $10 \mathrm{~cm}$ proximally and $10 \mathrm{~cm}$ distally, respectively, from the center of the injury to increase the sensitivity of the measurement (Sanchez et al., 2016; Rutkove et al., 2017).

\section{Injury Diagnosis and Return to Play Criteria}

Injuries were diagnosed by the medical team of the FCB Medical Department based on clinical history, physical examination, and US and MRI assessment. The establishment of return to play (RTP) criteria was addressed by the FCB Medical Department and team physicians follow the criteria expressed in FCB Muscle Guide 2019 (Barça Innovation Hub, 2020). The RTP (in days) started when the injury occurred and continued beyond the point when the player made his return to unrestricted match play (Hägglund et al., 2005). The RTP plan of FCB is individual avoiding re-injuries due to premature reinstatements. 
TABLE 1 | Individual values of L-BIA measurements $24 \mathrm{~h}$ after injury [contralateral non-injured side (1), injured side (2) in R, Xc, and PA], including tendinous ( $n=4)$, MTJ $(n=26)$, and MFJ $(n=7)$ injuries.

\begin{tabular}{|c|c|c|c|c|c|c|c|}
\hline \multirow{2}{*}{$\begin{array}{l}\text { Muscle } \\
\text { Injuries }\end{array}$} & \multirow[b]{2}{*}{$\begin{array}{l}\text { Anatomical } \\
\text { location }\end{array}$} & \multicolumn{2}{|c|}{$\mathrm{R}(\Omega)$} & \multicolumn{2}{|c|}{$\mathrm{Xc}(\Omega)$} & \multicolumn{2}{|c|}{ PA $\left({ }^{\circ}\right)$} \\
\hline & & $\begin{array}{l}\text { Non-injured side } \\
24 \text { h after injury (1) }\end{array}$ & $\begin{array}{l}\text { Injured side } 24 \text { h } \\
\text { after injury (2) }\end{array}$ & $\begin{array}{c}\text { Non-injured side } \\
24 \text { h after injury (1) }\end{array}$ & $\begin{array}{l}\text { Injured side } 24 \text { h } \\
\text { after injury (2) }\end{array}$ & $\begin{array}{c}\text { Non-injured side } \\
24 \mathrm{~h} \text { after injury (1) }\end{array}$ & $\begin{array}{l}\text { Injured side } 24 \text { h } \\
\text { after injury (2) }\end{array}$ \\
\hline 1 & $\mathrm{~T} 1$ & 33.5 & 32.4 & 13.9 & 13.8 & 22.5 & 23.1 \\
\hline 2 & $\mathrm{~T} 2$ & 38.8 & 38.0 & 17.2 & 17.0 & 23.9 & 24.1 \\
\hline 3 & T3 & 39.4 & 39.7 & 13.2 & 13.2 & 18.5 & 18.4 \\
\hline 4 & $\mathrm{~T} 4$ & 45.5 & 44.4 & 12.8 & 12.8 & 15.7 & 16.1 \\
\hline 5 & MTJ-Grade 1 & 32.0 & 29.0 & 16.0 & 14.0 & 26.6 & 25.8 \\
\hline 6 & MTJ-Grade 1 & 29.0 & 26.0 & 14.0 & 12.0 & 25.8 & 24.8 \\
\hline 7 & MTJ-Grade 1 & 47.0 & 43.0 & 18.0 & 16.0 & 21.0 & 20.4 \\
\hline 8 & MTJ-Grade 1 & 31.0 & 28.0 & 15.0 & 13.0 & 25.8 & 24.9 \\
\hline 9 & MTJ-Grade 1 & 37.4 & 34.6 & 14.0 & 11.9 & 20.5 & 19.0 \\
\hline 10 & MTJ-Grade 1 & 48.7 & 41.5 & 15.0 & 12.6 & 17.1 & 16.9 \\
\hline 11 & MTJ-Grade 1 & 35.8 & 31.8 & 12.0 & 10.6 & 18.5 & 18.4 \\
\hline 12 & MTJ-Grade 1 & 42.0 & 40.1 & 18.9 & 17.5 & 24.2 & 23.6 \\
\hline 13 & MTJ-Grade 1 & 53.6 & 52.1 & 11.2 & 9.8 & 11.8 & 10.7 \\
\hline 14 & MTJ-Grade 1 & 39.1 & 37.1 & 15.7 & 14.5 & 21.9 & 21.3 \\
\hline 15 & MTJ-Grade 1 & 49.0 & 47.4 & 15.9 & 13.7 & 18.0 & 16.1 \\
\hline 16 & MTJ-Grade 2 & 42.0 & 37.0 & 17.0 & 13.0 & 22.0 & 19.4 \\
\hline 17 & MTJ-Grade 2 & 34.0 & 32.0 & 13.0 & 10.0 & 20.9 & 17.4 \\
\hline 18 & MTJ-Grade 2 & 38.6 & 35.0 & 15.2 & 12.0 & 21.5 & 18.9 \\
\hline 19 & MTJ-Grade 2 & 44.8 & 38.5 & 17.3 & 13.6 & 21.1 & 19.5 \\
\hline 20 & MTJ-Grade 2 & 59.4 & 52.0 & 14.2 & 11.2 & 13.4 & 12.2 \\
\hline 21 & MTJ-Grade 2 & 32.3 & 32.2 & 13.4 & 11.5 & 22.5 & 19.7 \\
\hline 22 & MTJ-Grade 2 & 41.0 & 38.0 & 13.2 & 11.0 & 17.8 & 16.1 \\
\hline 23 & MTJ-Grade 2 & 32.1 & 29.1 & 13.5 & 11.5 & 22.8 & 21.6 \\
\hline 24 & MTJ-Grade 3 & 29.3 & 24.6 & 15.3 & 9.7 & 27.5 & 21.6 \\
\hline 25 & MTJ-Grade 3 & 44.0 & 36.0 & 14.0 & 10.0 & 17.7 & 15.5 \\
\hline 26 & MTJ-Grade 3 & 39.6 & 27.7 & 14.3 & 7.3 & 19.8 & 14.6 \\
\hline 27 & MTJ-Grade 3 & 43.3 & 34.4 & 20.8 & 12.2 & 25.7 & 19.5 \\
\hline 28 & MTJ-Grade 3 & 42.9 & 40.3 & 12.9 & 9.8 & 16.7 & 13.7 \\
\hline 29 & MTJ-Grade 3 & 32.0 & 27.0 & 13.4 & 10.3 & 22.7 & 20.9 \\
\hline 30 & MTJ-Grade 3 & 43.2 & 37.6 & 16.7 & 12.3 & 21.1 & 18.1 \\
\hline 31 & MFJ & 37.6 & 28.9 & 12.7 & 9.5 & 18.7 & 18.2 \\
\hline 32 & MFJ & 68.0 & 54.0 & 19.0 & 13.0 & 15.6 & 13.5 \\
\hline 33 & MFJ & 29.3 & 25.4 & 13.4 & 9.3 & 24.6 & 20.1 \\
\hline 34 & MFJ & 37.2 & 32.4 & 15.0 & 11.1 & 22.0 & 18.9 \\
\hline 35 & MFJ & 34.7 & 27.6 & 16.8 & 9.2 & 25.8 & 18.4 \\
\hline 36 & MFJ & 47.3 & 40.4 & 18.5 & 12.7 & 21.4 & 17.5 \\
\hline 37 & MFJ & 32.9 & 24.3 & 15.1 & 8.2 & 24.7 & 18.6 \\
\hline
\end{tabular}

R, Resistance; XC, Reactance; PA, phase angle; T, tendinous; MTJ, myotendinous junction; MFJ, myofascial junction.

\section{Data Analysis}

The normality of distribution in the variables was determined by the Shapiro-Wilk test and the homogeneity of variances by Levene's test. Normally distributed variables are shown as mean $\pm \mathrm{SD}$.

Repeated measures ANOVA test $2 \times 3$ was used to determine statistical differences between injured side respect to non-injured side in R, Xc, and PA considering contralateral non-injured side as reference value. In addition, different grades of severity (grades 1 to 3) of MTJ injuries were analyzed following the same statistical procedure.
One-way ANOVA test was used to determine statistical differences in the percentage difference of $\mathrm{R}, \mathrm{Xc}, \mathrm{PA}$, and RTP values, between tendinous, MTJ, and MFJ injuries, as well as between different grades of severity of MTJ injuries.

Both, repeated measures ANOVA and One-way ANOVA test, with multiple comparison tests by Bonferroni (homogeneity variances assumed) or Tamhane's T2 test (homogeneity variances not assumed) were used.

Discriminant Function Analysis was used to find a linear combination of features that separates muscle injuries L-BIA 


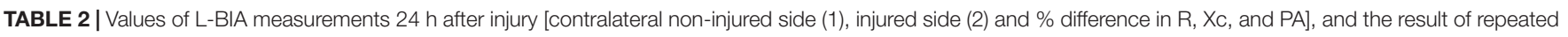
measures ANOVA test corresponding to tendinous, MTJ and MFJ.

\begin{tabular}{|c|c|c|c|c|}
\hline Tendinous, $(n=4)$ & Non-injured side $24 \mathrm{~h}$ after injury (1) & Injured side $24 \mathrm{~h}$ after injury (2) & Difference,\% & $F P$ value $(1-2)^{\mathrm{a} 1}$ \\
\hline $\mathrm{R}(\Omega)$ & $39.3 \pm 4.9$ & $38.6 \pm 5.0$ & $-1.8 \pm 1.8$ & $\begin{array}{l}4.119 \\
0.135\end{array}$ \\
\hline $\mathrm{Xc}_{\mathrm{c}}(\Omega)$ & $14.3 \pm 2.0$ & $14.2 \pm 1.9$ & $-0.5 \pm 0.6$ & $\begin{array}{l}2.455 \\
0.215\end{array}$ \\
\hline $\mathrm{PA}\left({ }^{0}\right)$ & $20.2 \pm 3.7$ & $20.4 \pm 3.8$ & $1.2 \pm 1.5$ & $\begin{array}{l}2.865 \\
0.189\end{array}$ \\
\hline MTJ, $(n=26)$ & Non-injured side $24 \mathrm{~h}$ after injury (1) & Injured side $24 \mathrm{~h}$ after injury (2) & Difference,\% & $F P$ value $(1-2)^{\mathrm{a} 2}$ \\
\hline $\mathrm{R}(\Omega)$ & $40.1 \pm 7.7$ & $35.8 \pm 7.4$ & $-10.7 \pm 6.3$ & $\begin{array}{l}65.640 \\
<0.001\end{array}$ \\
\hline $\mathrm{Xc}(\Omega)$ & $15.0 \pm 2.2$ & $12.0 \pm 2.2$ & $-20.0 \pm 10.1$ & $\begin{array}{l}76.565 \\
<0.001\end{array}$ \\
\hline $\mathrm{PA}\left({ }^{0}\right)$ & $20.9 \pm 3.9$ & $18.9 \pm 3.8$ & $-9.9 \pm 7.0$ & $\begin{array}{l}41.988 \\
<0.001\end{array}$ \\
\hline MFJ, $(n=7)$ & Non-injured side $24 \mathrm{~h}$ after injury (1) & Injured side $24 \mathrm{~h}$ after injury (2) & Difference,\% & $F$ P value $(1-2)^{\mathrm{a} 3}$ \\
\hline $\mathrm{R}(\Omega)$ & $41.0 \pm 13.1$ & $33.3 \pm 10.6$ & $-18.7 \pm 5.2$ & $\begin{array}{r}38.248 \\
0.001\end{array}$ \\
\hline $\mathrm{Xc}_{\mathrm{C}}(\Omega)$ & $15.8 \pm 2.4$ & $10.4 \pm 1.9$ & $-33.7 \pm 8.4$ & $\begin{array}{l}73.600 \\
<0.001\end{array}$ \\
\hline $\mathrm{PA}\left({ }^{0}\right)$ & $21.8 \pm 3.7$ & $17.9 \pm 2.1$ & $-17.0 \pm 8.4$ & $\begin{array}{r}19.509 \\
0.004\end{array}$ \\
\hline
\end{tabular}

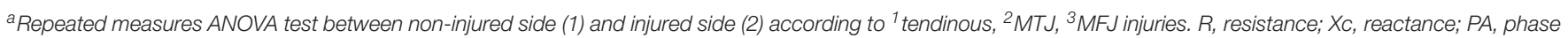
angle; MTJ, myotendinous junction; MFJ, myofascial junction.
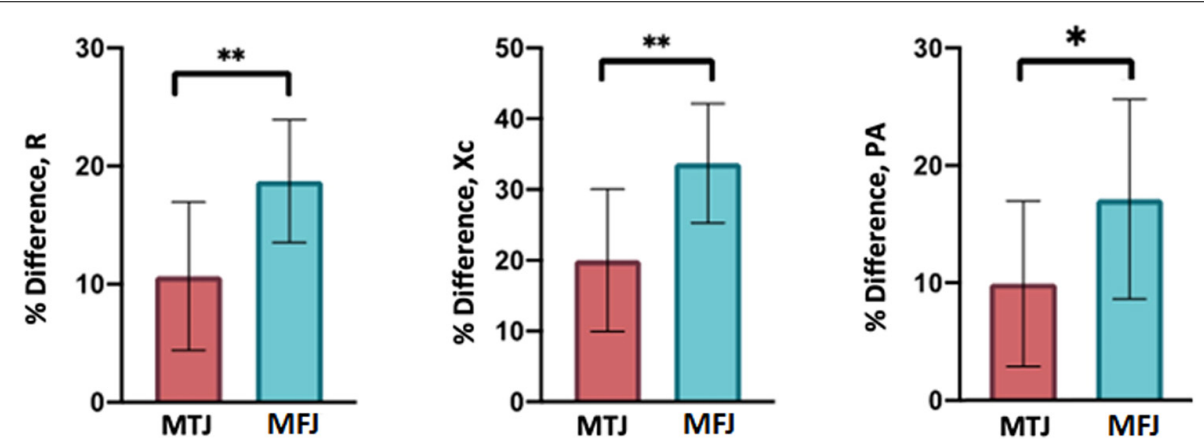

FIGURE 5 | Mean and SD of the \% difference in R, Xc, and PA of twenty-six MTJ (red) injuries and seven MFJ (blue). Results of One-way ANOVA between \% difference of MTJ respect to MFJ injuries, are also presented.

values (\% difference in $\mathrm{R}, \mathrm{Xc}$, and $\mathrm{PA}$ ) according to the grade of severity of MTJ injuries.

The statistical software IBM ${ }^{\circledR}$ SPSS $^{\circledR}$ version 22.0 (IBM Corp, Armonk, NY, United States) was used for data analysis. The level of statistical significance was set at $P<0.05$.

\section{RESULTS}

\section{Tendinous, MTJ and MFJ Injuries, Previously Diagnosed With MRI $24 \mathrm{~h}$ After Injury}

A total of 37 muscle injuries occurred between 2016-2017 and 2017-2018 seasons and evaluated by an MRI exam $24 \mathrm{~h}$ after injury, were grouped according to the myoconnective junction affected and classified following Pollock et al., 2014 in tendinous $(n=4), \operatorname{MTJ}(n=26)$, and MFJ $(n=7)$ injuries (Figures 2-4).

These injuries affected the long head of the biceps femoris $(n=12)$, the short head of the biceps femoris $(n=9)$, rectus femoris $(n=10)$, semitendinosus $(n=4)$ and semimembranosus $(n=2)$.

\section{L-BIA Measurements in Tendinous, MTJ and MFJ Injuries Diagnosed Previously by MRI $24 \mathrm{~h}$ After Injury}

Table 1 shows the individual values of L-BIA measurements $24 \mathrm{~h}$ after injury [resistance $(\mathrm{R})$, reactance $\left(\mathrm{Xc}_{\mathrm{C}}\right)$, and phase 


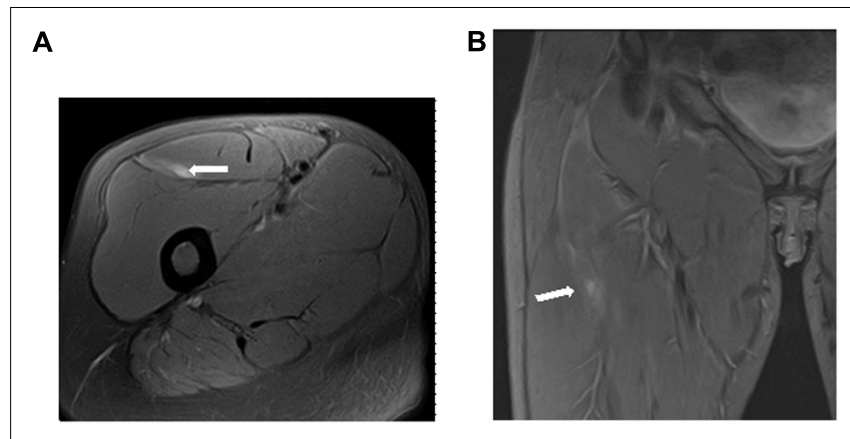

FIGURE 6 | Distal MTJ injury grade 1 of rectus femoris in axial (A) and coronal (B) T2 weighted fat-suppressed image. Small myofascial tear (arrow).
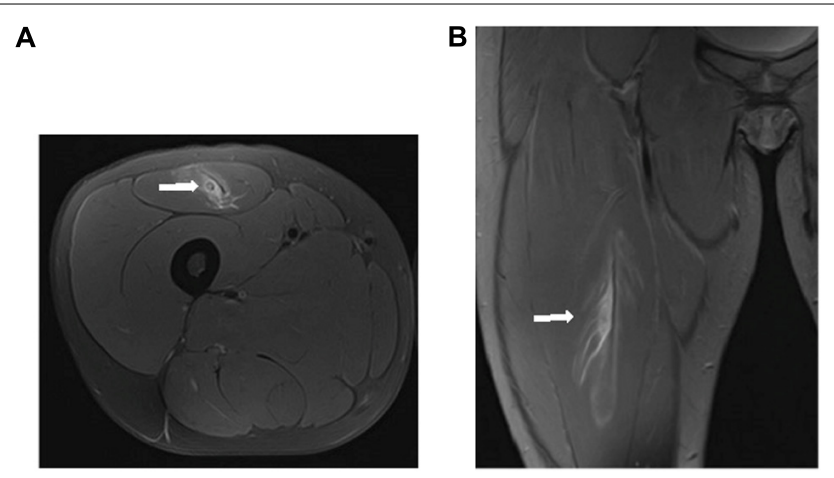

FIGURE 7 | Proximal MTJ injury grade 2 of rectus femoris in axial (A) and coronal (B) T2 weighted fat-suppressed image. Blurring of the muscle fibers in the lateral MTJ of the central septum, with a small hematoma. We can see that this is an overloaded rectus femoris.

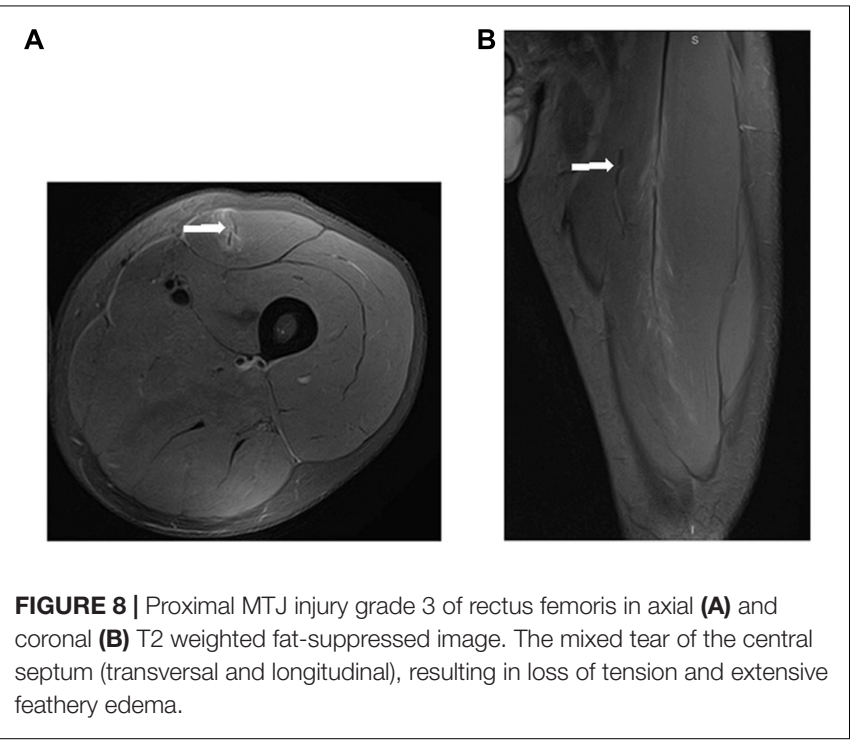

angle (PA)] of thirty-seven muscle injuries. According to anatomical location, injuries are classified as tendinous $(n=4)$, MTJ $(n=26)$ and MFJ $(n=7)$ in). Grades of severity of MTJ injuries (MTJ-Grade 1, MTJ-Grade 2, MTJ-Grade 3) are also displayed.

Table 2 describes the L-BIA measurements $24 \mathrm{~h}$ after injury, of thirty-seven muscle injuries, as mean \pm SD corresponding to tendinous $(n=4)$, MTJ $(n=26)$, and MFJ $(n=7)$ injuries and the percentage difference (Difference, $\%$ ) in resistance $(\mathrm{R})$, reactance $(\mathrm{Xc})$, and phase angle (PA). In addition, the result of the repeated measures ANOVA test between injured side compared to the non-injured side of $\mathrm{R}, \mathrm{Xc}$, and PA is reported.

Using repeated measures ANOVA test, anatomical changes related to tendinous injury were not reflected by L-BIA measurement through $\mathrm{R}, \mathrm{Xc}$, and $\mathrm{PA}(P>0.05), 24 \mathrm{~h}$ after injury. The percentage difference in $\mathrm{R}, \mathrm{Xc}$, and PA, $24 \mathrm{~h}$ after injury, were $-0.5 \% \sim-2 \%$. However, we found statistical significance $(P<0.01)$ for $\mathrm{R}, \mathrm{Xc}$, and $\mathrm{PA}$ for both MTJ and MFJ injuries. The MTJ injury results showed statistical significance $(P<0.001)$ in percentage difference of $\mathrm{R}, \mathrm{Xc}$, and $\mathrm{PA}$ in the injured side compared to the contralateral non-injured side $(-11 \%$ in $\mathrm{R},-20 \%$ in $\mathrm{Xc}$ and $-10 \%$ in PA), as well as MFJ injuries $(P<0.01)$ in percentage difference of $\mathrm{R}, \mathrm{Xc}$, and $\mathrm{PA}$ in injured side compared to the contralateral non-injured side $(-19 \%$ in $\mathrm{R},-34 \%$ in $\mathrm{Xc}$, and $-17 \%$ in $\mathrm{PA})$.

The One-way ANOVA test, with regard to MTJ and MFJ injuries, shows statistical significance for $\%$ difference in $\mathrm{R}$ $(F=9.673, P=0.004), \mathrm{Xc}(F=10.775, P=0.003)$ and statistical significance for PA $(F=5.155, P=0.030)$.

Figure 5 shows the mean and SD of percentage difference (\% Difference) in R, Xc, and PA, of MTJ and MFJ injuries, diagnosed by MRI exam $24 \mathrm{~h}$ after injury and evaluated by L-BIA measurements. In addition, the result of One-way ANOVA between \% difference of $\mathrm{R}, \mathrm{Xc}$ and PA in MTJ respect to \% difference of $\mathrm{R}, \mathrm{Xc}$, and PA in MFJ injuries.

\section{L-BIA Measurements of MTJ Grouped According to the Severity of the Injury Diagnosed Previously by MRI 24 h After Injury}

In a second analysis, 26 myotendinous junction (MTJ) injuries, evaluated by MRI $24 \mathrm{~h}$ after injury, were grouped according to the severity of the injury (Figures 6-8) follow BAMIC classification (Pollock et al., 2014) in grade $1(n=11)$, grade $2(n=8)$, and grade $3(n=7)$.

Table 3 presents the L-BIA measurements $24 \mathrm{~h}$ after the injury as mean $\pm \mathrm{SD}$ and percentage difference (Difference,\%) in $\mathrm{R}$, $\mathrm{Xc}$, and PA corresponding to the grade of severity of MTJ injury in grade $1(n=11)$, grade $2(n=8)$ and grade $3(n=7)$. In addition, the result of the repeated measures ANOVA test between injured side compared to the non-injured side of R, Xc, and PA is presented.

Using repeated measures ANOVA test, anatomical changes related to the grade of MTJ injuries were reflected by L-BIA measurement through $\mathrm{R}, \mathrm{Xc}$, and PA $(P<0.01), 24 \mathrm{~h}$ after injury for grade 1,2 , and 3 . 
TABLE 3 | Values of L-BIA measurements $24 \mathrm{~h}$ after injury [contralateral non-injured side (1), injured side (2) and \% difference in R, Xc, and PA] corresponding to the grade of MTJ injuries, and the result of repeated measures ANOVA test for $\mathrm{R}, \mathrm{Xc}$, and PA.

\begin{tabular}{|c|c|c|c|c|}
\hline MTJ-Grade 1, $(n=11)$ & Non-injured side $24 \mathrm{~h}$ after injury (1) & Injured side $24 \mathrm{~h}$ after injury (2) & Difference, $\%$ & $F P$ value $(1-2)^{b 1}$ \\
\hline $\mathbf{R}(\Omega)$ & $40.4 \pm 8.3$ & $37.3 \pm 8.4$ & $-7.9 \pm 3.7$ & $\begin{array}{l}40.405 \\
<0.001\end{array}$ \\
\hline Xc $(\Omega)$ & $15.1 \pm 2.3$ & $13.2 \pm 2.3$ & $-12.3 \pm 2.8$ & $\begin{array}{r}229.221 \\
<0.001\end{array}$ \\
\hline PA $\left({ }^{\circ}\right)$ & $21.0 \pm 4.5$ & $20.2 \pm 4.6$ & $-4.3 \pm 3.3$ & $\begin{array}{l}28.279 \\
<0.001\end{array}$ \\
\hline MTJ-Grade 2, $(n=8)$ & Non-injured side $24 \mathrm{~h}$ after injury (1) & Injured side 24 h after injury (2) & Difference, $\%$ & $F P$ value $(1-2)^{\mathrm{b} 2}$ \\
\hline $\mathrm{R}(\Omega)$ & $40.5 \pm 9.0$ & $36.7 \pm 7.0$ & $-8.8 \pm 4.4$ & $\begin{array}{r}20.788 \\
0.004\end{array}$ \\
\hline $\mathrm{Xc}_{\mathrm{C}}(\Omega)$ & $14.6 \pm 1.7$ & $11.7 \pm 1.1$ & $-19.5 \pm 3.7$ & $\begin{array}{c}108.784 \\
<0.001\end{array}$ \\
\hline $\mathrm{PA}\left({ }^{\circ}\right)$ & $20.3 \pm 3.2$ & $18.1 \pm 2.9$ & $-10.8 \pm 3.5$ & $\begin{array}{l}54.428 \\
<0.001\end{array}$ \\
\hline MTJ-Grade 3, $(n=7)$ & Non-injured side $24 \mathrm{~h}$ after injury (1) & Injured side 24 h after injury (2) & Difference, $\%$ & $F P$ value $(1-2)^{\mathrm{b} 3}$ \\
\hline $\mathrm{R}(\Omega)$ & $39.2 \pm 6.0$ & $32.5 \pm 6.0$ & $-17.1 \pm 7.3$ & $\begin{array}{r}31.968 \\
0.001\end{array}$ \\
\hline $\mathrm{Xc}_{\mathrm{c}}(\Omega)$ & $15.3 \pm 2.7$ & $10.2 \pm 1.7$ & $-32.7 \pm 9.8$ & $\begin{array}{r}42.505 \\
0.001\end{array}$ \\
\hline $\mathrm{PA}\left({ }^{\circ}\right)$ & $21.6 \pm 4.0$ & $17.7 \pm 3.1$ & $-17.8 \pm 6.6$ & $\begin{array}{r}32.618 \\
0.001\end{array}$ \\
\hline
\end{tabular}

${ }^{b}$ Repeated measures ANOVA test between non-injured side (1) and injured side (2) according to grade of MTJ injuries ${ }^{1}$ grade $1,{ }^{2}$ grade $2,{ }^{3}$ grade $3 . R$, resistance; $X \mathrm{c}$, reactance; PA, phase angle; MTJ, myotendinous junction; MFJ, myofascial junction.
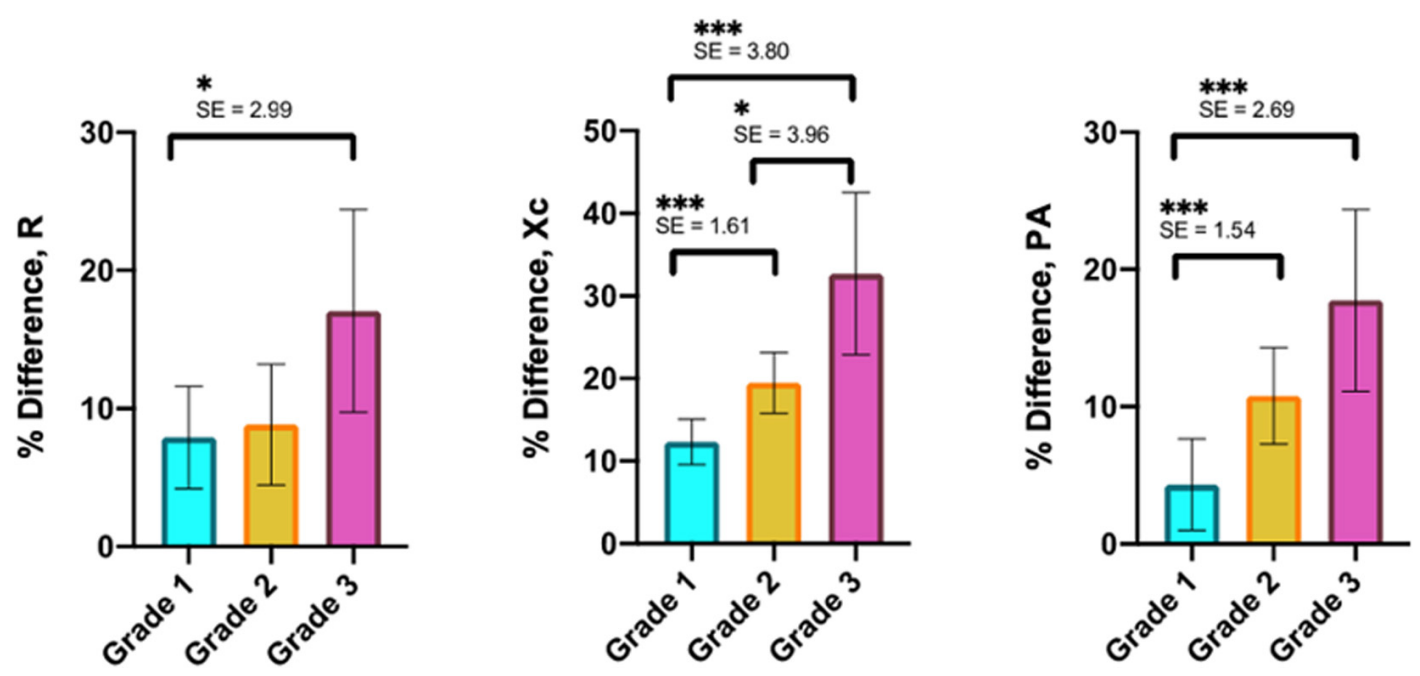

FIGURE 9 | Mean and SD of \% difference in R, Xc, and PA of MTJ injury grades 1-3. SE and results from post hoc test are also presented.

The One-way ANOVA test, regarding the MTJ injuries classified in grades 1,2 , and grade 3 , showed statistical significance in the $\%$ difference of $\mathrm{R}(F=7.630, P=0.003)$ and statistical significance for $\%$ difference of Xc $(F=26.964$, $P<0.001)$ and $\%$ difference of PA $(F=20.089, P<0.001)$.

Figure 9 shows the mean and SD of the \% difference in R, Xc, and PA, of twenty-six MTJ injuries classified as grade $1(n=11)$, grade $2(n=8)$, and grade 3 $(n=7)$ by MRI exam, 24-hour after injury. In addition, the results of Tamhane's T2 multiple comparison test revealed statistical differences $(P<0.001)$ in $\mathrm{Xc}$ and PA between grade 1 and grade 2, as well as between grade 1 and grade 3 .

Figure 10 shows the canonical discriminant functions, according to the grade of MTJ injuries, by Discriminant Function Analysis of percentage difference (\% difference) in R, Xc, and PA.

The function scores obtained through the standardized canonical discriminant function coefficients are: 


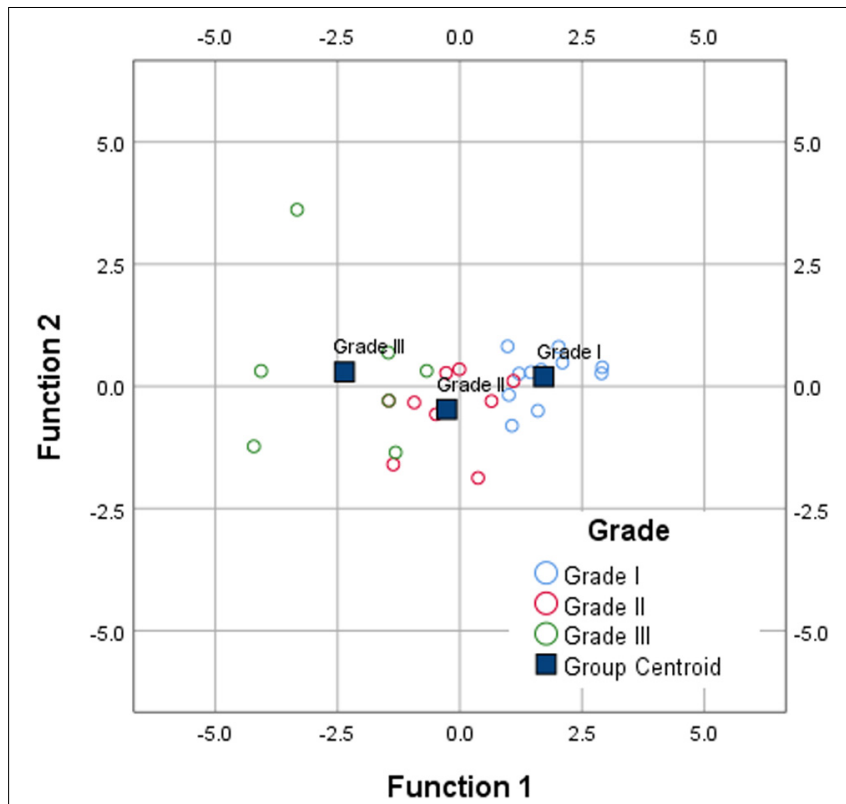

FIGURE 10 | Canonical discriminant functions for \% difference in R, $\mathrm{Xc}_{\mathrm{c}}$, and PA, according to the grade of MTJ injuries, of grade $1(n=11)$, grade 2 $(n=8)$, and grade $3(n=7)$.

FScore $1=3.198 \%$ difference $R-5.093 \%$ difference Xc $+2.701 \%$ difference $P A$

FScore $2=4.212 \%$ difference $R-4.746 \%$ difference $X c$

$$
+3.064 \% \text { difference } P A
$$

Both first and second function show the standardized coefficient for $\%$ difference $\mathrm{R}, \%$ difference Xc, and $\%$ difference PA. The magnitude of these coefficients indicate how strongly the discriminating variables affect the score. Thus, \% difference in Xc has the greatest impact of the three variables, on the first $(-5.093)$ and second $(-4.746)$ discriminant score, but especially in the first score. Therefore, $\mathrm{Xc}$ is the variable that most discriminates according to the grade of MTJ injuries by L-BIA measurements $24 \mathrm{~h}$ after injury.

\section{Return to Play (RTP) in MTJ and MFJ Injuries}

Table 4 present the RTP (in days), and the result of the One-way ANOVA test between MTJ and MFJ injuries and according to the grade of severity of MTJ injuries.

Using the One-way ANOVA test, and regarding MTJ and MFJ injuries, the RTP does not show statistical significance $(P>0.05)$.

Regarding the MTJ injuries classified in grades 1, 2, and grade 3 , we found statistical significance in days to RTP $(P<0.001)$. Tamhane's T2 reveals statistical difference $(S E=5.121, P=0.002)$ contrasting grade 1 ( $8 \pm 3$ days) with grade 3 (52 \pm 14 days) and
TABLE 4 | Return to play in MTJ and MFJ injuries.

\begin{tabular}{lcc}
\hline Anatomical Location (Sample size) & RTP, days & $\boldsymbol{F ~ P ~ v a l u e ~}^{\mathbf{1}}$ \\
\hline MTJ (26) & $25 \pm 22$ & $\begin{array}{l}2.277 \\
0.124\end{array}$ \\
MFJ (7) & $20 \pm 8$ & \\
\hline Grade of MTJ injury (Sample size) & RTP, days & $\boldsymbol{F ~ P ~ v a l u e ~}^{\mathbf{2}}$ \\
\hline Grade 1 (11) & $8 \pm 3$ & 39.517 \\
Grade 2 (8) & & $P<0.001$ \\
Grade 3 (7) & $14 \pm 10$ & \\
\hline
\end{tabular}

${ }^{1}$ One-way ANOVA between MTJ and MFJ injuries. ${ }^{2}$ One-way ANOVA among MTJ injuries according to severity.

also statistical difference $(S E=5.475, P=0.001)$ contrasting grade 2 (14 \pm 10 days) with grade 3 (52 \pm 14 days).

\section{DISCUSSION}

This second project of L-BIA developed by FCB Medical Department evaluates the capacity of the L-BIA method to differentiate muscle injuries according to anatomical location in tendinous, MTJ and MFJ, which are diagnosed by MRI exam $24 \mathrm{~h}$ after injury and classified according to The British Athletics Muscle Injury Classification (Pollock et al., 2014) considering the histoarchitectural approach to skeletal muscle injury (Balius et al., 2020). The most important finding is the good association between both MRI and L-BIA methods in myotendinous junction (MTJ) and myofascial junction (MFJ) injuries. Also, the fact that higher changes in Xc, and longer time to RTP are found in more severe MTJ injuries.

Comparing the injured side to non-injured side both for MTJ and MFJ injuries, the \% difference in L-BIA measurements $24 \mathrm{~h}$ after injuries are in concordance with findings by MRI exam $24 \mathrm{~h}$ after injury. The contralateral non-injured side is taken as reference due to the individual symmetry in L-BIA values between left and right muscle areas of the lower-limb in professional football players. By MRI exam, MFJ injuries show greater edema and greater bleeding than MTJ injuries, which justifies why the percentage difference (\% difference) of the injured side compared to the contralateral non-injured side is greater in MFJ injuries than in MTJ injuries. Both in MTJ and MFJ injuries the \% difference in $\mathrm{Xc}$ was greater than the \% difference in $\mathrm{R}$. According to our findings, to evaluate anatomical changes produced in MTJ and MFJ, $24 \mathrm{~h}$ after injury by L-BIA, the $\mathrm{Xc}$ is the most sensitive variable.

Although the tendinous injuries are the most severe cases (Crema et al., 2016) L-BIA method is completely insensitive to the anatomical changes produced in the tendinous injuries. Fortunately, they are also less common in professional football players (Crema et al., 2016). By MRI, the tendinous injuries show less edema and bleeding comparing to MTJ and MFJ injuries, and the intra-tendinous gap is considerably smaller. 
A normal tendon is a compact structure with tenocytes attached to a highly ordered fibrillar collagen matrix (ECM) composed of type-I collagen (65-80\% of its dry mass), and small leucine-rich proteoglycans that regulate collagen selfassembly into collagen fibrils, which in turn are ordered by the cell into collagen fibers (Snedeker and Foolen, 2017). In the intratendinous injury, tendon gap is smaller than those in muscle injuries and show generally less edema and bleeding than MTJ and MFJ injuries in MRI fluid-sensitive sequences. In acute intratendinous injuries, there is no major inflammatory component and its repair process goes along the lines of scar formation causing to the tensile strength of healed tendon like the healthy tendon (Nourissat et al., 2015). It should be clarified that differently to the hamstring free tendon, the intramuscular tendon has more vascularization (Brukner and Connell, 2016).

Comparing the percentage difference of MTJ injuries to the percentage difference of MFJ injuries, as in MRI exam $24 \mathrm{~h}$ after injury, both for edema produced in the area of the injury (\% difference $\mathrm{R}$ ) and the amount of cell disruption (\% difference $\mathrm{Xc}$ ), the L-BIA method distinguishes between MTJ and MFJ injuries. The \% difference in phase angle is more closely related to the changes produced in the Xc than with those produced in $\mathrm{R}$ for the geometric relationship between them (Lukaski, 1996; Lukaski et al., 2019).

In professional football, muscle injuries occur with major frequency at the myotendinous junction (MTJ) especially in hamstring muscle groups (Crema et al., 2016) whose main objective is the transmission of force (Balius et al., 2018). In this study, 26 out of 37 injuries occurred in the myotendinous junction, which were classified into grades 1,2 , and 3 , according to the severity of the injury. All of them showed a notable decrease in $\mathrm{R}$ and $\mathrm{Xc}$, being the largest change observed in $\mathrm{Xc}$. Furthermore, this change was even greater in grade 3 of the MTJ injury after comparing the injured side to the non-injured side. The \% difference of MTJ injuries grade 1 compared to the \% difference of MTJ injuries grade 2 and MTJ grade 3, elucidated that the more severe the injury is, higher changes in $\mathrm{R}$ and $\mathrm{Xc}$ are found, especially in $\mathrm{Xc}$ which is relate to muscle "gap" in agreement with the findings shown on the MRI exam $24 \mathrm{~h}$ after injury. Similar to wound healing (Lukaski and Moore, 2012), muscle injury is classified according to anatomical location, the \% difference in Xc (cell disruption, muscle "gap") is related with the severity of the injury. Regarding RTP (in days), it was not found differences between MTJ and MFJ injuries. However, according to severity of MTJ injuries, it was found differences among days to RTP and MTJ grades 1, 2, and 3. The injuries with the highest degree of severity were associated with longer time to RTP.

The decision on the days to RTP, is conditioned by the severity of the injury (Pedret et al., 2015; Balius et al., 2018, Balius et al., 2020) and by the myoconnective junction involved. The days to RTP are strongly associated with changes in Xc (muscular fibers retraction quantified by \% different of Xc) i.e., the severity of injuries is reflected by higher changes in $\mathrm{Xc}$ and longer time to RTP. Injury recovery is related to a readjustment of the $\mathrm{Xc}$ parameter closer to the value of the contralateral non-injured side with \% difference lower than 15\% in those muscle injuries of high degree of severity according to the muscle "gap" (Nescolarde et al., 2013). It is important mentioning that for measurements on injured muscles with L-BIA until RTP time point, each player is his own reference (Nescolarde et al., 2013). The role of MRI is key for the diagnosis and prognosis of injuries, and therefore, a great tool for RTP prediction. However, it is not the only criterion to take into account. The decision on time to RTP by FCB physicians are based on club's guidance, taking into account not only imaging criteria but also specific tests, GPS assessment, and even the player's psycho-emotional state.

\section{CONTRIBUTION}

Localized bioimpedance is a complementary method to MRI and US as currently it can only quantify MTJ and MFJ injuries. In addition, it could be useful for the medical team, physiotherapists, and physical trainers in the diagnosis of muscle injury helping in day-to-day decision-making. L-BIA measurements are carried out using a phase-sensitive impedance instrument at $50 \mathrm{kHz}$, robust and easy to apply, and economically feasible.

\section{LIMITATION}

To validate L-BIA as a complementary method to MRI and US, it is necessary to extend this study to other professional football teams to increase the sample size, as well as to include female athletes.

\section{CONCLUSION}

We conclude that L-BIA is a tool able to differentiate between MTJ and MFJ injuries. Additionally, it discriminates between MTJ grade 3 injury and grades 1 and 2 . The sensitivity of L-BIA method is shown to be higher in the percentage difference of Xc $24 \mathrm{~h}$ after injury, which is related to muscle cell disruption. In addition, more severe injures presented higher $\%$ difference in $\mathrm{Xc}$ and longer time to RTP.

\section{DATA AVAILABILITY STATEMENT}

The raw data supporting the conclusions of this article will be made available by the authors, without undue reservation.

\section{ETHICS STATEMENT}

Ethics approval was obtained from the Medical Committee of Barça Innovation Hub in Futbol Club Barcelona according to principles of the Helsinki Declaration for experiments 
with human beings. The participants provided oral and written informed consent before participation in the study during a period of 2016-2017 and 2017-2018. The patients/participants provided their written informed consent to participate in this study.

\section{AUTHOR CONTRIBUTIONS}

All authors designed the experiments, analyzed the data, revised the manuscript, and approved the final version of the manuscript. LN processed the data and prepared the tables and figures. LN and GR wrote the manuscript.

\section{REFERENCES}

Ahmad, C. S., Redler, L. H., Ciccotti, M. G., Maffulli, N., Longo, U. G., and Bradley, J. (2013). Evaluation and management of hamstring injuries. Am. J. Sports Med. 41, 2933-2947. doi: 10.1177/0363546513487063

Askling, C. M., Nilsson, J., and Thorstensson, A. (2010). A new hamstring test to complement the common clinical examination before return to sport after injury. Knee Surg. Sports Traumatol. Arthrosc. 18, 1798-1803. doi: 10.1007/ s00167-010-1265-3

Balius, R., Alomar, X., Pedret, C., Blasi, M., Rodas, G., Pruna, R., et al. (2018). Role of the extracellular matrix in muscle injuries: histoarchitectural considerations for muscle injuries. Orthop. J. Sports Med. 6:2325967118795863. doi: 10.1177/ 2325967118795863

Balius, R., Blasi, M., Pedret, C., Alomar, X., Peña-Amaro, J., Vega, J. A., et al. (2020). A histoarchitectural approach to skeletal muscle injury: searching for a common nomenclature. Orthop. J. Sports Med. 8:2325967120909090. doi: $10.1177 / 2325967120909090$

Barça Innovation Hub (2020). Barça Innovation Hub/Muscle Injury Guide - Preventing and Treating Muscle Injuries in Football. Available online at: https://barcainnovationhub.com/muscle-injury-guide-preventing-andtreating-muscle-injuries-in-football/ (accessed May 24, 2020).

Brooks, J. H. M., Fuller, C. W., Kemp, S. P. T., and Reddin, D. B. (2006). Incidence, risk, and prevention of hamstring muscle injuries in professional rugby union. Am. J. Sports Med. 34, 1297-1306. doi: 10.1177/0363546505286022

Brukner, P., and Connell, D. (2016). Serious thigh muscle strains': beware the intramuscular tendon which plays an important role in difficult hamstring and quadriceps muscle strains. Br. J. Sports Med. 50, 205-208. doi: 10.1136/bjsports2015-095136

Crema, M. D., Guermazi, A., Tol, J. L., Niu, J., Hamilton, B., and Roemer, F. W. (2016). Acute hamstring injury in football players: association between anatomical location and extent of injury-A large single-center MRI report. J. Sci. Med. Sport. 19, 317-322. doi: 10.1016/j.jsams.2015.04.005

Ekstrand, J., Hägglund, M., and Waldén, M. (2011). Injury incidence and injury patterns in professional football: the UEFA injury study. Br. J. Sports Med. 45, 553-558. doi: 10.1136/bjsm.2009.060582

Ekstrand, J., Healy, J. C., Waldén, M., Lee, J. C., English, B., and Hägglund, M. (2012). Hamstring muscle injuries in professional football: the correlation of MRI findings with return to play. Br. J. Sports Med. 46, 112-117. doi: 10.1136/ bjsports-2011-090155

Ekstrand, J., Waldén, M., and Hägglund, M. (2016). Hamstring injuries have increased by $4 \%$ annually in men's professional football, since 2001: a 13-year longitudinal analysis of the UEFA Elite Club injury study. Br. J. Sports Med. 50, 731-737. doi: 10.1136/bjsports-2015-095359

Elliott, M. C., Zarins, B., Powell, J. W., and Kenyon, C. D. (2011). Hamstring muscle strains in professional football players: a 10-year review. Am. J. Sports Med. 39, 843-850. doi: 10.1177/0363546510394647

Engebretsen, L., Soligard, T., Steffen, K., Alonso, J. M., Aubry, M., Budgett, R., et al. (2013). Sports injuries and illnesses during the london summer olympic games 2012. Br. J. Sports Med. 47, 407-414. doi: 10.1136/bjsports-2013092380

\section{FUNDING}

This study was supported by the Electronic and Biomedical Instrumentation Research Group of Electronic Engineering Department, Universitat Politècnica de Catalunya and FCB Medical Department, Barcelona, Spain.

\section{ACKNOWLEDGMENTS}

We especially thank the players of Futbol Club Barcelona and Ana Núñez-Nescolarde for their collaboration in this study.

Hägglund, M., Waldén, M., Bahr, R., and Ekstrand, J. (2005). Methods for epidemiological study of injuries to professional football players: developing the UEFA model. Br. J. Sports Med. 39, 340-346. doi: 10.1136/bjsm.2005. 018267

Heiderscheit, B. C., Sherry, M. A., Silder, A., Chumanov, E. S., and Thelen, D. G. (2010). Hamstring strain injuries: recommendations for diagnosis, rehabilitation, and injury prevention. J. Orthop. Sports Phys. Ther. 40, 67-81. doi: 10.2519/jospt.2010.3047

Junge, A., Engebretsen, L., Mountjoy, M. L., Alonso, J. M., Renström, P. A., Aubry, M. J., et al. (2009). Sports injuries during the summer olympic games 2008. Am. J. Sports Med. 37, 2165-2172. doi: 10.1177/0363546509339357

Lukaski, H., Vega Diaz, N., Talluri, A., and Nescolarde, L. (2019). Review: classification of hydration in clinical conditions: indirect and direct approaches using bioimpedance. Nutrients 11:809. doi: 10.3390/nu11040809

Lukaski, H. C. (1996). Biological indexes considered in the derivation of the bioelectrical impedance analysis. Am. J. Clin. Nutr. 64(3 Suppl.), 397S-404S. doi: 10.1093/ajcn/64.3.397S

Lukaski, H. C. (2013). Evolution of bioimpedance: a circuitous journey from estimation of physiological function to assessment of body composition and a return to clinical research. Eur. J. Clin. Nutr. 67(Suppl. 1), S2-S9. doi: 10.1038/ ejcn.2012.149

Lukaski, H. C., and Moore, M. (2012). Bioelectrical impedance assessment of wound healing. J. Diabetes Sci. Technol. 6, 209-212. doi: 10.1177/ 193229681200600126

Lukaski, H. C., and Piccoli, A. (2012). "Bioelectrical impedance vector analysis for assessment of hydration in physiological states and clinical conditions," Handbook of Anthropometry, ed. V. Preedy (London, UK: Springer), 287-315.

Mueller-Wohlfahrt, H. W., Haensel, L., Mithoefer, K., Ekstrand, J., English, B., McNally, S., et al. (2013). Terminology and classification of muscle injuries in sport: a consensus statement. Br. J. Sports Med. 47, 342-350. doi: 10.1136/ bjsports-2012-091448

Nescolarde, L., Lukaski, H., De Lorenzo, A., de-Mateo-Silleras, B., RedondoDel-Río, M. P., and Camina-Martín, M. A. (2016). Different displacement of bioimpedance vector due to $\mathrm{Ag} / \mathrm{AgCl}$ electrode effect. Eur. J. Clin. Nutr. 70, 1401-1407. doi: 10.1038/ejcn.2016.121

Nescolarde, L., Yanguas, J., Lukaski, H., Alomar, X., Rosell-Ferrer, J., and Rodas, G. (2013). Localized bioimpedance to assess muscle injury. Physiol. Meas. 34, 237-245. doi: 10.1088/0967-3334/34/2/237

Nescolarde, L., Yanguas, J., Lukaski, H., Alomar, X., Rosell-Ferrer, J., and Rodas, G. (2015). Effects of muscle injury severity on localized bioimpedance measurements. Physiol. Meas. 36, 27-42. doi: 10.1088/0963334/36/1/27

Nescolarde, L., Yanguas, J., Terricabras, J., Lukaski, H., Alomar, X., Rosell-Ferrer, J., et al. (2017). Detection of muscle gap by L-BIA in muscle injuries: clinical prognosis. Physiol. Meas. 38, L1-L9. doi: 10.1088/1361-6579/aa7243

Nourissat, G., Berenbaum, F., and Duprez, D. (2015). Tendon injury: from biology to tendon repair. Nat. Rev. Rheumatol. 11, 223-233. doi: 10.1038/nrrheum. 2015.26

Patel, A., Chakraverty, J., Pollock, N., Chakraverty, R., Suokas, A. K., and James, S. L. (2015). British athletics muscle injury classification: a reliability study for 
a new grading system. Clin. Radiol. 70, 1414-1420. doi: 10.1016/j.crad.2015. 08.009

Pedret, C., Rodas, G., Balius, R., Capdevila, L. L., Bossy, M., Vernooij, R. W. M., et al. (2015). Return to play after soleus muscle injuries. Orthop. J. Sports Med. 3:2325967115595802. doi: 10.1177/2325967115595802

Pollock, N., Patel, A., Chakraverty, J., Suokas, A., James, S. L., and Chakraverty, R. (2016). Time to return to full training is delayed and recurrence rate is higher in intratendinous ('c') acute hamstring injury in elite track and field athletes: clinical application of the british athletics muscle injury classification. $\mathrm{Br} . J$. Sports Med. 50, 305-310. doi: 10.1136/bjsports-2015-094657

Pollock, N., Steven, L. J. J., Lee, J. C., and Chakraverty, R. (2014). British athletics muscle injury classification. Br. J. Sports Med. 48, 1347-1351. doi: 10.1136/ bjsports-2013-093302

Reurink, G., Goudswaard, G. J., Tol, J. L., Almusa, E., Moen, M. H., Weir, A., et al. (2014). MRI observations at return to play of clinically recovered hamstring injuries. Br. J. Sports Med. 48, 1370-1376. doi: 10.1136/bjsports-2013-0 92450

Rutkove, S., Pacheck, A., and Sanchez, B. (2017). Sensitivity distribution simulations of surface electrode configurations for electrical impedance myography. Muscle Nerve 56, 887-895. doi: 10.1002/mus. 25561

Rutkove, S. B. (2009). Electrical impedance myography: background, future state and future directions. Muscle Nerve 40, 936-946. doi: 10.1002/mus.21362

Rutkove, S. B., Fogerson, P. M., Garmirian, L. P., and Tarulli, A. W. (2008). Reference values of $50-\mathrm{kHz}$ electrical impedance myography. Muscle Nerve 38, 1128-1132. doi: 10.1002/mus.21075

Sanchez, B., Pacheck, A., and Rutkove, S. B. (2016). Guidelines to electrode positioning for human and animal electrical impedance myography research. Sci. Rep. 6:32615.

Schneider-Kolsky, M. E., Hoving, J. L., Warren, P., and Connell, D. A. (2006). A comparison between clinical assessment and magnetic resonance imaging of acute hamstrings injuries. Am. J. Sports Med. 34, 1000-1007. doi: 10.1177/ 0363546505283835

Snedeker, J. G., and Foolen, J. (2017). Tendon injury and repair - a perspective on the basic mechanisms of tendon disease and future clinical therapy. Acta Biomater. 63, 18-36. doi: 10.1016/j.actbio.2017. 08.032

Valle, X., Alentorn-Geli, E., Tol, J. L., Hamilton, B., Garret, W. E., Pruna, R., et al. (2017). Muscle injuries in sports: a new evidence-informed and expert consensus-based classification with clinical application. Sports Med. 2017, 1241-1253. doi: 10.1007/s40279-016-0647-1

Vermeulen, R., Almusa, E., Buckens, S., Six, W., Whiteley, R., Reurink, G., et al. (2019). Complete resolution of a hamstring intramuscular tendon injury on MRI is not necessary for a clinically successful return to play. Br. J. Sports Med. [Epub ahead of print]. doi: 10.1136/bjsports-2019101808

Wangensteen, A., Tol, J. L., Roemer, F. W., Bahr, R., Dijkstra, H. P., Crema, M. D., et al. (2017). Intra- and interrater reliability of three different MRI grading and classification systems after acute hamstring injuries. Eur. J. Radiol. 89, 182-190. doi: 10.1016/j.ejrad.2017.02.010

Conflict of Interest: The authors declare that the research was conducted in the absence of any commercial or financial relationships that could be construed as a potential conflict of interest.

Copyright (c) 2020 Nescolarde, Terricabras, Mechó, Rodas and Yanguas. This is an open-access article distributed under the terms of the Creative Commons Attribution License (CC BY). The use, distribution or reproduction in other forums is permitted, provided the original author(s) and the copyright owner(s) are credited and that the original publication in this journal is cited, in accordance with accepted academic practice. No use, distribution or reproduction is permitted which does not comply with these terms. 